\title{
SOBERANIA E EXCEÇÃO NO PENSAMENTO DE CARL SCHMITT
}

\author{
Newton Bignotto* \\ bignotto@ufmg.br
}

RESUMO $O$ artigo procura demonstrar que ocorre, no pensamento de Carl Schmitt, a fusão entre a figura do legislador tal como tratada na Antigüidade e aquela do soberano moderno. Resulta disso que o conceito de exceção passa a ocupar o núcleo da vida política.

Palavras-chave Legislador; soberania; exceção; Sieyès.

ABSTRACT The article tries to demonstrate that in Carl Schmitt's thought, there is a fusion between the concept of ancient legislator and that of modern sovereign. The result is that the concept of exception became nuclear to the political life.

Keywords Legislator; sovereignty; exception; Sieyès.

O crescente interesse pela obra de Carl Schmitt não fez desaparecer o mal-estar que acompanha seus leitores e intérpretes quanto à sua biografia e o significado de sua adesão ao nazismo no curso dos anos trinta. Para alguns, esse fato é decisivo e macula de tal forma seu trabalho, que não há razões suficientes para que a originalidade de algumas de suas proposições seja objeto

* Professor do Departamento de Filosofia da UFMG. Artigo recebido em junho de 2008 e aprovado em novembro de 2008. 
de uma atenção especial. Nessa perspectiva, a solidariedade entre a vida do pensador e sua obra seria tamanha que ela descortinaria o sentido último de sua investigação. ${ }^{1}$ Numa outra vertente interpretativa, os vínculos inegáveis do pensador com o regime totalitário não trariam implicações diretas para os que se dedicam a estudá-lo, sobretudo quando o foco do interesse são seus escritos anteriores a 1933, quando ele defendeu muitos aspectos da Constituição de Weimar e criticou aqueles que recusavam sua validade. De alguma maneira, esses intérpretes pretendem adotar um ponto de vista analítico próximo da neutralidade, quando se trata de estudar o pensador da política e da teoria constitucional. Sem negar os fatos lamentáveis da vida do filósofo, esses leitores recusam-lhes pertinência epistêmica, e pretendem se refugiar em uma leitura interna dos argumentos schmittianos. ${ }^{2}$

De nossa parte, acreditamos que não há como não se interrogar sobre as vinculações existentes entre a filosofia de um autor e suas escolhas políticas, sobretudo quando elas são tão desastrosas como é o caso de Schmitt. Isso não significa recusar uma apreciação do esforço reflexivo do pensador, mas sim reconhecer a importância epistêmica de uma tomada de posição que não se fez à distância dos acontecimentos e sem uma implicação direta em seu desenvolvimento. Carl Schmitt não foi certamente o estimulador do nazismo e nem mesmo seu mentor intelectual. No entanto, ele mesmo não autorizaria uma leitura que implicaria numa forma qualquer de neutralização da política e de seus conceitos. Como ele diz no Conceito do político: "todos os conceitos, representações e vocábulos políticos têm um sentido polêmico; eles têm em vista um antagonismo concreto, estão ligados a uma situação concreta cuja conseqüência última é um agrupamento amigo-inimigo". ${ }^{3}$ Nesse sentido, não há como separar inteiramente seu destino pessoal e suas escolhas daquilo que ele escreveu. Ao mesmo tempo não podemos ceder à tentação de encontrar na superfície de seus escritos uma ligação de causa e efeito entre suas reflexões e suas posições políticas durante os primeiros anos do regime nazista. A questão de fundo permanece sendo aquela da relação entre a filosofia política e a vida política, que se torna ainda mais aguda quando o autor concernido optou por apoiar um dos regimes políticos mais terríveis da história do Ocidente.

1 De forma vigorosa e argumentada, essa é a posição defendida por Zarka em: CHARLES YVES ZARKA. Contre Carl Schmitt. Paris: PUF, 2004.

2 Essa é a conduta de Freund em muitos de seus escritos, em particular em: JULIEN FREUND. L'essence du politique. Paris: Éditions Sirey, 1986.

3 CARL SCHMITT. La notion de politique. Paris: Calmann-Lévy, 1972, p. 71. Retomamos aqui a tradução proposta por Bernardo Ferreira em : BERNARDO FERREIRA. O risco do político. Belo Horizonte: Editora UFMG, 2004, p. 37. 
Essas considerações demarcam o lugar no qual pretendemos conduzir nossas investigações, mas não seu objeto. Conscientes do problema, vamos retornar à obra do autor para tentar compreender alguns de seus elementos centrais, mesmo sabendo que isso não nos conduzirá necessariamente a responder às indagações subjacentes ao destino da obra de maneira definitiva. De fato, permanece no horizonte de nossas questões o problema da ligação entre filosofia e vida política, mas esse tema exigiria um trabalho tanto em torno da questão em sentido amplo quanto especificamente sobre os escritos de nosso autor, que a abordam diretamente, o que ultrapassa em muito nossas pretensões nesse texto. Nosso horizonte de investigação será o de suas considerações sobre a soberania e exceção. Como esses problemas estão distribuídos em várias obras de Schmitt, vamos concentrar nossos estudos em alguns aspectos da Teologia política e nas conseqüências de suas formulações principais para a compreensão dos fundamentos da vida política na contemporaneidade. Em particular, vamos buscar compreender quais argumentos podem ter servido para levar Schmitt a aderir ao partido nazista em 1933. Com isso estamos implicitamente deixando de lado as leituras de sua obra que atribuem a um suposto oportunismo político a responsabilidade por seus atos, mesmo preservando a crítica a seus procedimentos. ${ }^{4}$ Não pretendemos, no entanto, abandonar o terreno da análise conceitual, para mergulhar no universo biográfico. De certa forma, preocupa-nos abordar a questão de um ponto de vista negativo e apontar não as razões pelas quais Schmitt fez o caminho em direção ao partido nazista, mas sim por que ele pode não julgá-lo absurdo ou em contradição com suas convicções teóricas.

As interpretações recentes da obra de nosso autor têm sido marcadas pela importância concedida ao problema do estado de exceção e as conseqüências políticas da aceitação dessa idéia como fazendo parte do universo jurídico e político das democracias ocidentais. Agamben em seu livro Estado de exceção ${ }^{5}$ aponta para a solidariedade conceitual entre a Teologia política e A ditadura como a chave para compreender a démarche de nosso autor. Para ele, ao insistir no livro de 1921 sobre a distinção entre "ditadura comissarial" e "ditadura soberana", ${ }^{6}$ Schmitt cria as condições para fazer do conceito de soberania o núcleo de suas considerações sobre a relação entre política e direito e definir o estado de exceção como o grande problema da filosofia

4 Nesse ponto nos distanciamos da posição defendida por Renato Lessa em: RENATO LESSA. A política como ela é...:Carl Schmitt e o realismo político como agonia e aposta. In: Agonia, aposta e ceticismo. Belo Horizonte: Editora UFMG, 2003, p. 28.

5 GIORGIO AGAMBEN. Stato di eccezione. Torino: Bollati Boringhieri, 2004.

6 CARL SHMITT. La dictadura. Madrid: Alianza, 1985. 
política contemporânea. ${ }^{7}$ Ancorar o estado de exceção na ordem jurídica é, para Agamben, o passo decisivo dado pelo pensador alemão. Essa afirmação se ilumina, quando recordamos que, para o filósofo italiano, o século XX marcou um momento de virada na tradição política ocidental, pois fez da exceção uma prática normal de governo. Nas palavras de Agamben: "Um dos caracteres essenciais do estado de exceção, -a abolição provisória da distinção entre poder legislativo, executivo e judiciário-, mostra sua tendência a transformarse em uma prática durável de governo". ${ }^{8}$

A interpretação de Agamben tem o mérito de elucidar os vínculos entre um dos conceitos centrais da obra de Schmitt e algumas reflexões atuais sobre o destino das sociedades ocidentais. Além disso, ela fornece um ponto de partida interessante para a investigação do que poderíamos chamar de periculosidade da filosofia política schmittiana ao mostrar como a idéia de gestão da exceção conduz as sociedades políticas a assumir riscos incompatíveis com qualquer forma de democracia. A démarche de Agamben é instigante, mas, ao acentuar o fato de que o recurso às práticas políticas oriundas do espaço definido pelo estado de exceção é algo amplo na história de várias nações ocidentais, ele deixa na sombra as rupturas teóricas que sustentam essa tendência, o que, a nosso ver, não dizem respeito apenas a um conflito interno ao pensamento jurídico e a seus limites.

A esse respeito, Jorge Dotti realça em um de seus trabalhos o fato de que é essencial para a compreensão da filosofia de nosso autor investigar o uso que ele faz da idéia de exceção. ${ }^{9}$ Para o estudioso, Schmitt lida com a questão a partir de sua oposição ao que é normal nos diversos sistemas legais. ${ }^{10}$ Ora, esse ponto de partida não visa conferir importância ontológica ao conceito, mas apenas formular o espaço de existência daquilo que escapa à compreensão dos que se guiam pela ordem jurídica estabelecida, pois, como afirma Dotti, "as categorias legais são incapazes de descobrir o sentido do que é novo". ${ }^{11}$ Se levarmos em conta essas considerações, compreenderemos a razão pela qual em Schmitt o conceito de soberania está intimamente ligado àquele de exceção. Ao tentar encontrar o estatuto ontológico do lugar que escapa ao normal, Schmitt se encontra em um dilema, pois a recusa de atribuir um significado positivo qualquer ao que escapa da ordem jurídica, pode significar simplesmente que estamos diante de fatos contingentes, que não podem ser 
objeto de nenhuma teorização. Essa solução devolveria o problema a seu leito tradicional e os expulsaria do terreno daquilo que pode ser pensado. Ora, o grande esforço de nosso autor é justamente encontrar um acento teórico para esse espaço entre o dentro e o fora, que, segundo Agamben, constitui "estrutura topológica do estado de exceção". ${ }^{12}$

Uma das formulações mais conhecidas e polêmicas de Schmitt está presente logo no início de seu Teologia política. Para ele: "Soberano é aquele que decide do estado de exceção". ${ }^{13}$ Essa definição coloca em cena os dois conceitos que nos interessam aqui, o de soberania e o de exceção. Cabe observar, no entanto, que uma parte da crítica recente tem tomado o problema do ponto de vista da associação entre soberania e estado de exceção e deixado na sombra, o fato de que a idéia de exceção é ela mesma problemática e merece ser investigada. ${ }^{14}$ É claro que os problemas não estão separados, mas ao acentuar na frase o estado, interpretado seja como um momento, seja como uma forma específica de ordenação das forças políticas, nos esquecemos de que Schmitt adverte logo no início do livro que ele está lidando com uma "noção limite" e que, portanto, a referência às situações ditas normais não nos ajuda a formular a questão. Dizendo de outra maneira, é necessário lembrar que o objeto das considerações do autor se encontra fora do alcance dos instrumentos conceituais que empregamos para pensar a política na vida comum das nações. Isso implica em dizer, que a pergunta sobre o estatuto ontológico da exceção é um problema incontornável, pois permite circunscrever a verdadeira dificuldade que é pensar nos limites da experiência humana.

Schmitt não pretende com sua definição expor uma nova idéia do que seja a soberania, ou mesmo sua ligação direta com o problema da constituição, seu foco está nos casos limites, no problema dos meios de efetivação da vontade daquele que deve tomar as decisões que dizem respeito a aspectos essenciais da vida política como aquele da segurança, do interesse público, etc. ${ }^{15}$ Como resume muito bem Ferreira, trata-se de pensar o lugar no qual "a aniquilação do direito se confunde com sua própria criação". ${ }^{16} \mathrm{O}$ ponto a ser ressaltado é o fato de que Schmitt nega aos sistemas jurídicos um conteúdo imanente, que os livraria da contingência que assola a vida política. O solo, para a formulação

12 GIORGIO AGAMBEN. Stato di eccezione. P. 48.

13 CARL SCHMITT. Théologie politique. Paris: Gallimard, 1988, p. 15.

14 Para uma leitura lúcida da questão: BERNARDO FERREIRA. O risco do político. P 108-111.

15 CARL SCHMITT. Théologie politique. P. 16.

16 BERNARDO FERREIRA. O risco do político. P. 101. 
do problema da validade da norma, é o mesmo da construção da vida em comum dos homens. ${ }^{17}$

Na seqüência do texto, Schmitt adverte para o fato de que uma Constituição não pode prever quando será necessário reconhecer a exceção, “no máximo poderá dizer quem tem o direito de intervir nesses casos". ${ }^{18}$ Nesses momentos, o soberano aparece nitidamente. "Ele está na margem da ordem jurídica normalmente em vigor, estando ao mesmo tempo submetido a ela, pois a ele incumbe decidir se a Constituição deve ser suspensa em sua totalidade". ${ }^{19}$ Estamos, portanto, em um espaço paradoxal, uma vez que a ordem jurídica parece evocar o soberano para a cena política, ao mesmo tempo em que arrisca de ser extinta. $\mathrm{O}$ fato de que o aparecimento do soberano pareça escandaloso para alguns autores, deriva, segundo Schmitt, de que eles não souberam entender a lição de Bodin, para quem, segundo $S c h m i t t,{ }^{20}$ a soberania é evocada sempre como uma exceção. A exceção faz aparecer na cena política uma outra tópica importante do pensamento de nosso autor: a decisão. Quando a ordem política está em suspenso, o soberano é aquele que decide de tudo, e esse ato concerne todo o corpo político.

Para pensar esse espaço paradoxal, Schmitt faz questão de mostrar que ele não pode ser confundido com a anarquia, ou com o caos; há algo que subsiste, e esse algo deve ser identificado com o Estado. Nesses momentos, segundo ele, "a decisão se libera de toda obrigação normativa e torna-se absoluta em sentido próprio. No caso de exceção, o Estado suspende o direito em virtude de um direito de autoconservação, como se diz". ${ }^{21}$ A dificuldade para se pensar o lugar da exceção é justamente que ela não pode ser subsumida, nem remetida a nada. Ela é a "decisão em estado puro", para nosso autor. ${ }^{22}$ Ora, os pensadores do direito de seu tempo, especialmente Kelsen, haviam antevisto a dificuldade em se teorizar sobre a exceção e, por conseqüência sobre a soberania, e, por isso, foram levados, segundo Schmitt, a simplesmente recusar os dois temas. ${ }^{23}$ Essa postura, longe de resolver a questão, impediu que ela emergisse na cena teórica, mas não na vida prática, no interior da qual a política se resolve.

De maneira resumida, poderíamos dizer que Schmitt alinha três conceitos diferentes e os toma como ponto de partida de qualquer reflexão que queira 
dar conta não apenas das condições da vida normal, mas da vida em comum em toda sua extensão; são esses conceitos: soberania, exceção e decisão. Com essas ferramentas, um pensamento que queira estar em sintonia com o que ele chama de "filosofia da vida concreta", poderá enfrentar o desafio de se lidar com os casos de exceção, que no fundo são para nosso autor, os únicos que importam. ${ }^{24}$

A associação direta entre soberania e exceção levou Schmitt a descurar de outras tópicas da tradição filosófica nas quais alguns dos problemas que o interessam recebem um tratamento diferente daquele que ele propõe. Estamos pensando aqui na figura do legislador, que desde a antiguidade povoa as terras da filosofia política. Tomando como referência a experiência de Sólon em Atenas, descobrimos alguns pontos de aproximação com a questão da exceção que podem nos interessar. É claro que no contexto grego não podemos falar de soberania, mas a questão da criação das leis é parte fundamental não apenas da filosofia grega, mas, o que nos interessa mais diretamente, da vida política dos antigos.

Na Grécia antiga, duas figuras diferentes se referem ao momento de criação das leis: a do fundador das cidades e a do legislador. Enquanto a primeira, o oikist, se confunde com freqüência com os heróis dos mitos de fundação, ${ }^{25}$ a segunda aponta para os momentos de crise das cidades, quando suas referências legais entram em colapso e apela-se para um ator específico para reordenar a vida da cidade. Entra em cena nesses momentos o que se chamava de legislador, o nomothetés. Segundo Szegedy-Maszak, a intervenção desse personagem na vida da cidade seguia alguns passos que podem ser resumidos em três etapas. Num primeiro momento, a crise na cidade é de tal amplitude que ela reconhece não poder enfrentá-la, por isso lança mão de uma figura extraordinária para tentar resolver. Num segundo momento, o legislador consegue enfrentar os graves problemas que ameaçam destruir a polis e propõe um novo código de leis. Por fim, com a crise resolvida, ele se vai, evitando se imiscuir na vida normal da cidade. ${ }^{26}$

O que nos interessa aqui é a proximidade entre as crises que na antiguidade levavam as cidades a apelar para um legislador externo e o conceito de exceção em Carl Schmitt. Também para os antigos tratava-se de um momento no qual as estruturas de direito tradicionais entravam em falência e era preciso

24 Idem, p. 25.

25 JAMES F. Mcglew. Tyranny and political culture in Ancient Greece. Ithaca: Cornell University Press, 1993, p. 18-19.

26 ANDREW SZEGEDY-MASZAK. Legends of the Greek Lawgivers. Greek, Roman and Byzantine Studies, Duke University, vol. 19, p.208-210, (1978). 
retomar o sentido da vida em comum, sem, no entanto, clamar por um herói mítico, que todos sabiam que seria ineficaz naquele momento. $\mathrm{O}$ recurso a um ator externo alerta-nos, no entanto, para seu caráter excepcional e para os cuidados que devem acompanhar o apelo a essa tópica. Como mostrou Nicole Loraux, Sólon encarnou na antiguidade o modelo desse personagem e nos fez ver os riscos inerentes à sua condição. Para a helenista, tudo se passa como se ele ocupasse um lugar que não pode ser designado na topologia normal do poder, pois se encontra no meio das partes em luta, o que no campo de batalha era conhecido como o métaichmion. "O Paradoxo de Sólon-diz ela- é que esse meio do meio no qual se é sempre dois, ele queira se manter sozinho, se identificando talvez com esse centro problemático". ${ }^{28}$

O perigo escondido nesse lugar, no qual não se separa com segurança a guerra civil da disputa entre as partes do corpo político, reside no fato de que a passagem daquele que ocupa o lugar paradoxal do legislador para o centro da vida política da cidade faz nascer um tirano. Ou seja, a exceção do métaichmion deve permanecer como tal se não quisermos oferecer à cidade um poder que ultrapassa sua capacidade de resolver seus conflitos internos. O próprio Sólon, que se negou a permanecer em Atenas, uma vez concluída sua obra, advertiu seus compatriotas do erro que cometeram ao não entender a natureza do poder excepcional do qual ele havia disposto: "Depus minhas armas diante do centro dos estrategas, e disse que era mais sábio do que os que não viam que Psístrato aspirava à tirania, e mais corajoso do que os que não ousavam se opor a ele. Mas não me escutaram"29.

No início da modernidade, o tema da soberania, que vinha sendo elaborado desde o final da Idade Média, ${ }^{30}$ veio a colocar no centro das preocupações dos pensadores europeus a questão da origem do poder e de seu fundamento. Não se tratava mais de investigar os mecanismos de elaboração das leis, mas de descobrir como elas podiam se sustentar como a referência principal para a criação e manutenção das sociedades políticas. Se Bodin, como quer Schmitt, teve um papel essencial nesse processo, ${ }^{31}$ nada nos leva a crer, como parece sugerir o pensador alemão, que depois dele a noção de soberania não tenha

27 NICOLE LOURAUX. Sólon au milieu de la lice. In: Aux origines de l'hellénisme. Mélanges Henri van Effenterre. Paris, 1984, p. 199-214.

28 Idem, p. 205.

29 DIÓGENES LAÉRCIO, Vie, doctrines et sentences des philosophes illustres. Paris: Garnier-Flammarion, 1965,2 vol,l,2

30 Sobre essa questão: RAQUEL KRITSCH. Soberania. A construção de um conceito. São Paulo: Humanitas, 2002.

31 Sobre esse problema ver: ALBERTO DE BARROS. A teoria da soberania de Jean Bodin. São Paulo: Unimarco editora, 2001. 
acompanhado o desenvolvimento das nações modernas. ${ }^{32}$ Ao contrário, o problema da soberania se tornou parte essencial da maioria das doutrinas políticas da modernidade e não apenas daquelas que se ocuparam do direito. O que no interessa notar é que esse desenvolvimento do problema do soberano não fez desaparecer aquele do legislador. Em outros termos, ao colocar o acento no tema da origem da lei, a filosofia ocidental não deixou de se preocupar com o problema de sua efetivação. O legislador moderno passou a ser pensado no interior de um quadro conceitual diferente daquele da antiguidade e marcado pela presença da questão da soberania. Mas, se os dados fundamentais do problema mudaram com as condições históricas, a questão de pensar o momento efetivo de criação das leis não perdeu sua importância, longe disso.

Talvez um bom exemplo da confluência dessas duas tópicas seja o pensamento de Rousseau. No pensador de Genebra converge a preocupação com a soberania, concentrada no elemento popular, com aquele do legislador. No Contrato Social, ele estabelece o vínculo entre o tema do contrato e o de sua efetivação por meio de um legislador: "Pelo pacto social conferimos existência e vida ao corpo político: trata-se agora de conceder-lhe movimento e vontade pelo legislador". ${ }^{33}$ A referência ao legislador coloca juntos o problema do soberano e aquele do responsável pela efetivação do pacto. Se para ele, o problema da origem do poder se resolvia pela referência ao povo e à necessidade de se escutar a vontade geral, para escolher as leis que deveriam dar vida ao corpo político, essa aparente simplicidade se desfaz, quando se trata de pensar os meios de construção do quadro legal. O que Rousseau admite é que nas condições ideais para a fundação de um novo corpo político, é preciso um princípio ativo, que seja capaz de transformar um conjunto de vontades particulares em uma unidade política.

Esse princípio é o legislador que, segundo ele, "é em todos os sentidos um homem extraordinário no interior do Estado". ${ }^{34}$ Para levar a cabo sua tarefa, ele deve "ter uma inteligência superior, viver todas as paixões humanas e não experimentar nenhuma". ${ }^{35}$ Rousseau formula com exatidão as características que regem o lugar de atuação daquele que é o personagem mais destacado na cena da criação de novas leis. Não há dificuldade em identificar esse lugar ocupado pelo legislador com o lugar da exceção em Schmitt. Também o legislador de Rousseau deve partir de um agregado de homens, que não possui

32 CARL SCHMITT. Théologie politique. P. 27.

33 ROUSSEAU. Du Contat Social. In: Oeuvres complètes. Paris: Gallimard, 1964. Vol. III, Livro II, VI, p. 378. 34 Idem, II, VII, p. 382.

35 Idem, p. 381. 
uma referência normativa estável, mas deseja afirmar sua unidade política. Essa tarefa parece, no entanto, tão gigantesca para o pensador genebrino que ele termina por concluir: "seriam necessários deuses para dar leis aos homens". ${ }^{36}$ O que ele afirma, portanto, é que esse é um lugar paradoxal, comandado pelo fato de que "aquele que redige as leis não tem e não deve ter nenhum direito legislativo, e o povo mesmo não pode, mesmo se o desejasse, se despojar desse direito incomunicável". ${ }^{37}$

Ao não admitir que o povo possa ser representado, quando se trata de seus direitos inalienáveis, Rousseau acaba por não encontrar uma solução direta para o paradoxo que enuncia. Não nos interessa, no entanto, continuar a examinar a questão do legislador em seu pensamento. Importa sublinhar dois pontos. $\mathrm{O}$ primeiro diz respeito ao fato de que a liberdade é um valor inalienável e que, portanto, não pode ser desprezada sem que se sigam as piores conseqüências para o corpo político. No horizonte da constituição de um corpo político há, pois, um referencial que não é o fruto de uma escolha, mas decorre da própria condição natural do homem. O segundo ponto importante para nós é que o soberano prima sobre o legislador, o que faz com que a tarefa do segundo esteja sempre subordinada aos imperativos da soberania popular. Do ponto de vista prático, isso coloca uma série de problemas, como bem viram os deputados da Constituinte, ${ }^{38}$ mas garante um mecanismo de salvaguarda contra qualquer vontade particular, que se arvore a resolver a crise decorrente da falência da ordem normativa partindo de princípios derivados de sua pura decisão.

Cabe notar que em Schmitt o problema do legislador está ausente dos textos nos quais ele realiza a ligação entre soberania e exceção. Se ele é fecundo ao apontar o fato de que as sociedades atuais não podem deixar de lado os acontecimentos que ameaçam sua identidade jurídica, pelo simples fato de que o direito não dá conta dessas situações, ele não avalia em toda sua extensão os riscos que o momento de exceção faz correr os regimes voltados para a defesa da liberdade como referência última da vida em comum. Nesse sentido, é interessante notar a preocupação que ele demonstra de se aproximar de Sieyès.

Na Teoria da Constituição ${ }^{39}$ nosso autor chama a atenção para o fato de que, logo no começo da Revolução francesa, o povo se declarou detentor do poder constituinte e coube a Sieyès estabelecer a distinção entre o poder

36 Idem, p. 381

37 Idem,p. 383.

38 Ver a esse respeito: TIMOTHY TACKETT. Par la volonté du peuple. Comment les députés de 1789 sont dévenus révolutionnaires. Paris: Albin Michel, 1997.

39 CARL SCHMITT. Teoria de la Constitución. Madrid: Editorial de derecho privado, 1956. 
constituinte, que cabe à nação em sua integralidade e o poder constituído, que opera no curso da vida normal dos povos. ${ }^{40}$ Para Schmitt, a referência à nação é fundamental, pois permite a afirmação do desejo implícito no gesto dos constituintes de se unir por uma razão de ordem política. Ou seja, ao apontar a nação, e não o povo, como origem do poder constituinte evita-se o caráter vago e muitas vezes obscuro da referência ao elemento popular. Para o deputado francês, a nação é sempre a referência última, o que leva Schmitt a identificar esse lugar com aquele da exceção: "o poder constituinte não está vinculado a formas jurídicas e procedimentos, quando atua no interior dessa propriedade inalienável, está 'sempre em estado de natureza". ${ }^{41}$

É verdade que ao apelar para a representação como meio para tornar possível a feitura de uma Constituição, perde-se o caráter democrático radical -presente em Rousseau- da idéia de vontade geral, mas isso não altera o fato de que na origem do processo está uma exceção, algo que não pode ser contido nos ordenamentos jurídicos prévios de uma nação. Na continuação da discussão sobre a natureza do poder constituinte, Schmitt lembra que, segundo Sieyès:

O poder constituinte não se extingue por um ato de seu exercício. Muito menos se apóia em algum título jurídico. Quando o monarca renuncia voluntariamente a seu poder constituinte e reconhece aquele do povo, este último não reside no ato jurídico da renúncia do rei. A razão de sua eficácia está exclusivamente em sua existência política. ${ }^{42}$

A referência a Sieyès é precisa, quando consideramos a emergência da idéia de poder constituinte no seio da Revolução francesa, mas é necessário investigar se esse momento possui as mesmas características da idéia de exceção em Schmitt. Para ele, o estado de exceção não pode existir num vazio total. Essa afirmação visa apontar para o lugar fundamental que a nação, enquanto expressão da vontade política unitária de um povo, possui na determinação da vida política em toda sua extensão, em particular quando não possui qualquer determinação jurídica, que é o que Schmitt chama, com já vimos, de exceção.

Os pontos de confluência do pensamento dos dois autores parecemnos claros. Resta investigar as diferenças, para saber se de fato do poder constituinte, pensado durante a Revolução francesa, chegamos a uma idéia da 
exceção, que coloca a decisão como fundamento último da vida política. As idéias do deputado francês, citadas pelo jurista alemão, foram desenvolvidas em escritos que, em sua maior parte, se concentram nos anos 1789 e 1790 . Em particular, foi seu discurso dos dias 20 e 21 de julho de 1789, perante a Assembléia Nacional, que trouxeram à baila suas concepções a respeito do poder constituinte. ${ }^{43}$ Nele Sieyès mostra que o poder político é uma decorrência do estabelecimento de uma Constituição. Para mostrar como isso se efetiva, ele recorre a conceitos correntes em seu tempo, como aqueles de vontade geral e outros presentes nas filosofias de Hobbes e Locke. Ele indica, sobretudo, que "todos os poderes públicos, sem distinção, são uma emanação da vontade geral, todos provêem do povo, quer dizer, da nação". ${ }^{44}$

Esses pontos podem sugerir que a proximidade entre os dois autores é grande, mas essa impressão se desfaz quando recordamos que para Sieyès : "toda união social e, por conseguinte, toda constituição política tem por objetivo manifestar, estender e assegurar os direitos do homem e do cidadão". ${ }^{45}$ Além do mais, ele acredita que o homem naturalmente procura seu bem-estar e emprega todos os meios para consegui-lo. Com isso, subsiste no pensamento do constituinte traços essenciais dos pensadores liberais, inclusive a defesa da primazia das liberdades individuais, que devem ser preservadas pela Constituição. ${ }^{46} \mathrm{O}$ ponto que nos parece importante de ressaltar aqui é a importância dos direitos humanos como base e fundamento de toda constituição de um Estado livre. Ou seja, para Sieyès, o lugar designado por Schmitt, como aquele do estado de exceção, encontra seus fundamentos num conjunto de direitos que transcendem as configurações particulares das nações. Os direitos humanos presidem o esforço constitucional e não podem ser deixados de lado no momento em que uma nação escolhe seus rumos e sua ordenação jurídica. Ora, nada é mais distante do pensamento de Schmitt do que a primazia acordada aos direitos humanos no processo de feitura de uma Constituição. Isso não quer dizer que eles não possam ser incorporados por decisão do poder constituinte à sua obra, mas sim que não podem ser considerados seu fundamento. Nesse sentido a convergência do pensamento dos dois autores se mostra ilusória, mesmo se Schmitt tenha se mostrado tão cioso em se aproximar da obra do pensador francês.

43 SIEYÈS. Préliminaire de la Constitution. Reconnaissance et exposition raisonnèe des droits de l'homme et du citoyen. In: FRANÇOIS FURET; RAM HALÉVI (Org). Orateurs de la Révolution française. Paris: Gallimard, 1989, p. 1004-1018.

44 Idem, p. 1015.

45 Idem, p. 1005

46 Idem, p. 1010. 
Se voltarmos nossa atenção para o problema da ditadura, quando Schmitt fornece um exemplo interessante da confluência entre o problema da exceção e o da norma, alguns pontos de nossa investigação se esclarecem. $\mathrm{O}$ autor separa ditadura de despotismo, como separa a ditadura em duas formas ${ }^{47}$. Como lembra Ferreira: "a ditadura é pensada em Schmitt como um instituto do direito público cujo conteúdo, alcance e competência, em última análise, não podem ser delimitados juridicamente" ${ }^{48}$ Ou seja, a ditadura não é pensada como uma forma de governo, mas como uma força, que atua no limite da vida política, lá onde as leis são forjadas. A ditadura comissarial age fora dos limites legais, mas com o intuito de preservar a norma. Desse ponto de vista, Schmitt não a vê como algo que ameaça destruir totalmente a ordem, mas sim como um instrumento, que procura conciliar norma e realidade. ${ }^{49}$

A ditadura soberana é o verdadeiro problema, pois ela aparece nos momentos em que a ordem legal colapsou e não pode nem mesmo ser dita com algo em suspenso. O ditador aqui é o soberano em sua força máxima, mas também em sua máxima indeterminação. Todo o problema está em que as diferenças conceituais entre as duas formas de ditadura não parecem se reproduzir nos fatos. Não há como colocar um limite à ação do ditador, pois senão ele não seria um, e, portanto, no terreno dos fatos, não há como impedir que uma forma de ditadura se transforme em outra. Schmitt identifica a ditadura soberana com o poder constituinte tal como pensado por de Sieyès. ${ }^{50}$ Curiosamente, ele cita a experiência da Convenção francesa entre 1792 e 1795 com um primeiro exemplo de ditadura soberana. ${ }^{51}$ Ora, não lhe ocorre mostrar que se de fato a França procurou elaborar nesse período várias Constituições, uma delas de inspiração girondina e outra de inspiração jacobina, nenhuma chegou a governar a vida política francesa. Ao contrário, o exercício pela Convenção do poder, que Schmitt chamaria de ditatorial, terminou na criação de um governo pelo terror e não na criação de instituições de direito. O exemplo escolhido para ilustrar a ditadura soberana é uma demonstração explícita de sua incapacidade de criar leis e de sua tendência a fazer do uso abusivo da força a regra das disputas políticas. ${ }^{52}$

47 CARL SHMITT. La dictadura. p. 93.

48 BERNARDO FERREIRA. O risco do político. P. 103.

49 Idem, p. 105.

50 Para um estudo do pensamento constitucional de Sieyès ver: PASQUALE PASQUINO. Emmanuel Sieyès: his constitutional republicanism. In: BIANCAMARIA FONTANA (ORG). The invention of the modern Republic. Cambridge: Cambridge University Press, 2006.

51 BERNARDO FERREIRA. O risco do político. p. 111.

52 Ver a esse respeito: ROGER DUPUY. La republique jacobine. Terreur, guerre et gouvernement révolutionnaire. Paris: Éditions du Seuil, 2005, p. 35-77; 117-172. 
Tudo se passa, portanto, como se para Schmitt a figura do legislador, presente ao longo de quase toda a história da filosofia política, e a figura do soberano, própria às filosofias da modernidade, se fundissem em uma só. Com esse movimento, a idéia de exceção perde seu vínculo com aquela de contingência e passa a ocupar o núcleo da argumentação schmittiana. A vida política contemporânea passa a ser regida, portanto, pelo que lhe escapa. Se na vida ordinária isso nem sempre acontece, a exceção é como um ator maior de um drama que não deixará de ocorrer, uma vez que não parece possível para Schmitt encontrar formas estáveis de poder ao longo da história. Ao contrário, ele não cansou de denunciar o liberalismo por sua tendência a buscar a neutralização da política, como mostrou muito bem Bernardo Ferreira. Para nosso autor, uma sociedade pacificada é uma sociedade sem conflitos o que quer dizer que é uma sociedade morta e incapaz de fazer face aos desafios do tempo, sobretudo daqueles lançados por seus inimigos. Ora, se a busca da estabilidade é uma ameaça para a vida política, a exceção ronda a democracia como uma parte necessária de sua existência.

Voltando às nossas considerações iniciais, parece-nos que a periculosidade da obra schmittiana não está na denúncia dos riscos implícitos à toda democracia constitucional, o que o levou a tentar defender as instituições alemãs no curso da segunda década do século XX. Ao realizar a fusão entre duas figuras diferentes do pensamento político, ele acabou por aceitar a incorporação em um único sujeito de características diferentes de atores políticos. O soberano de Schmitt perdeu assim a abstração que o define em pensadores como Rousseau, para se encarnar num ditador, que habita os limites da vida política. Como nada pode reger de fora esse espaço, o ditador não possui freios, ou limites para sua ação. De alguma forma, a interpretação schmittiana do momento de criação das leis, suprime todas as salvaguardas, uma vez que faz da ordem jurídica uma decisão de uma vontade libertada dos constrangimentos impostos por acordos prévios, ou por valores aceitos pela tradição. O hiper-realismo de Schmitt acaba por tornar concreto, o que em Maquiavel é quase uma figura ideal e em Rousseau um ser paradoxal.

Talvez, por isso, Hitler tenha parecido uma solução plausível no meio da crise pela qual passava a Alemanha e que parecia requerer a identificação de um novo paradigma político, o que só pode ser feito por aquele que decide do lugar do soberano. O que parece ter escapado à Schmitt é que esse soberanolegislador dos tempos atuais, liberado dos constrangimentos impostos pelo recurso ao freio do direito natural, mas também da regra prudencial, que comandava o comportamento dos legisladores da antiguidade, só poderia se consolidar como um tirano, muito mais terrível do que aqueles que em Atenas 
ocuparam o poder depois que Sólon cumpriu sua tarefa. Num contexto no qual se perderam as salvaguardas representadas pela tradição ou pela natureza, a decisão erigida em princípio da vida política e encarnada em um ator concreto, seja ele um homem ou um partido, é a porta para uma aventura á qual continuamos a estar exposto, mas que já mostrou sua face terrível no curso do último século. Nessa lógica, a adesão ao nazismo de Schmitt deixa de poder ser pensada como um acaso, para se transformar numa possibilidade inscrita no coração mesmo de seu pensamento. Ela não decorre, é verdade, de uma necessidade interna de sua filosofia, mas nada lhe obstaculizava o caminho, na medida em que a adesão ao tirano é sempre de ordem prática e não um desiderato teórico. Se a obra de Schmitt, ao longo dos anos, não perdeu sua capacidade de provocar uma reflexão instigante sobre a natureza do político, também não oferece um obstáculo convincente aos riscos proporcionados pelo recurso aos instrumentos extremos da vida política.

\section{Referências}

AGAMBEN, Giorgio. Stato di eccezione. Torino: Bollati Boringhieri, 2004.

BARROS, Alberto. A teoria da soberania de Jean Bodin. São Paulo: Unimarco editora, 2001.

DIÓGENES LAÉRCIO, Vie, doctrines et sentences des philosophes illustres. Paris: Garnier-Flammarion, 1965, 2 vol,I,2.

DOTTI, Jorge. Some remarks on Carl Schmitt's notion of "exception". Kriterion, $n^{\circ}$ 94, p. 24-35. (1996).

DUPUY, Roger. La republique jacobine. Terreur, guerre et gouvernement révolutionnaire. Paris: Éditions du Seuil, 2005.

FERREIRA, Bernardo. O risco do político. Belo Horizonte: Editora UFMG, 2004.

FREUND, Julien. L'essence du politique. Paris: Éditions Sirey, 1986.

KRITSCH, Raquel. Soberania. A construção de um conceito. São Paulo: Humanitas, 2002.

LESSA, Renato. A política como ela é...:Carl Schmitt e o realismo político como agonia e aposta. In: Agonia, aposta e ceticismo. Belo Horizonte: Editora UFMG, 2003.

LOURAUX, Nicole. Sólon au milieu de la lice. In: Aux origines de l'hellénisme. Mélanges Henri van Effenterre. Paris, 1984, p. 199-214.

MACGLEW, J F. Tyranny and political culture in Ancient Greece. Ithaca: Cornell University Press, 1993.

PASQUINO. Pasquale. Emmanuel Sieyès: his constitutional republicanism. In: BIANCAMARIA FONTANA (ORG). The invention of the modern Republic. MCambridge: Cambridge University Press, 2006.

ROUSSEAU, J,-J. Du Contat Social. In: Oeuvres complètes. Paris: Gallimard, 1964. Vol I. 
SCHMITT, Carl. Teoria de la Constitucion. Madrid: Editorial de derecho privado, 1956.

SCHMITT, Carl. Théologie politique. Paris: Gallimard, 1988.

SCHMITT, Carl.. La notion de politique. Paris: Calmann-Lévy, 1972.

SHMITT, Carl. La dictadura. Madrid: Alianza, 1985.

SIEYĖS. Préliminaire de la Constitution. Reconnaissance et exposition raisonnèe des droits de l'homme et du citoyen. In: FRANÇOIS FURET; RAM HALÉVI (Org). Orateursde la Révolution française. Paris: Gallimard, 1989, p. 1004-1018.

SZEGEDY-MASZAK. A. Legends of the Greek Lawgivers. In: Greek, Roman and Byzantine Studies, Duke University, vol 19, p.208-210, (1978).

TACKETT, T. Par la volonté du peuple. Comment les députés de 1789 sont dévenus révolutionnaires. Paris: Albin Michel, 1997.

ZARKA. Carles Yves. Contre Carl Schmitt. Paris: PUF, 2004. 